\title{
Beliefs about Using Technology in the Mathematics Classroom: Interviews with Pre-service Elementary Teachers
}

\author{
Cheng-Yao Lin \\ Southern Illinois University Carbondale, IL, USA
}

Received 10 April 2007; accepted 10 November 2007

\begin{abstract}
This study explored the efficacy of web-based workshops in topics in elementary school mathematics in fostering teachers' confidence and competence in using instructional technology, and thereby promoting more positive attitudes toward using computers and Internet resources in the mathematics classroom. It consisted of in-depth interviews of selected workshop participants in order to provide information on whether the goals of the workshops were realized, and if so, in what ways these goals were accomplished. The interviews showed that most of the students in the experimental group felt comfortable using web-based resources in teaching elementary school mathematics. It was also found through the interviews that all students agreed that the workshops helped them become more confident in using computers to teach mathematics. The findings of this study provide further compelling evidence to support the recommendations of many national reports, such as the NCTM Professional Standards for School Mathematics (2000), to substantially increase the role of instructional technology in the contemporary mathematics classroom.
\end{abstract}

Keywords: Mathematics Education, Technology, Web-Based, Preservice Teacher, Teacher Education.

\section{INTRODUCTION}

According to National Council of Teachers Mathematics, (2000), "technology is essential in teaching and learning mathematics; it influences the mathematics that is taught and enhances students' learning. Teachers' attitudes play an important role in using technology in teaching and learning mathematics" (p. 24). It is very important to improve teachers' attitudes toward using computers in the classroom because it may enhance mathematics teaching and learning. However, many preservice and in-service teachers are unfamiliar with the types of technology available for teachers. Also, many teachers lack the knowledge of how to properly

Correspondence to: Cheng-Yao Lin, Assist. Prof. Dr. Department of Curriculum and Instruction, Southern Illinois University Carbondale, 625Wham Dr., Mailcode 4610, Carbondale, IL, 62901, USA

E-mail:cvlin@.siu.edu

Copyright (C) 2008 by Moment

E-ISSN: 1305-8223 incorporate technology in the classroom (Doering, Huffman, \& Hughes, 2003). Research on technology integration in mathematics education has examined the effectiveness of spreadsheets and dynamic geometry software on achievement (Isikal \& Askar, 2005), computers and 2D geometric learning (Olkun, Altun, \& Smith, 2005), and dynamic geometry sketches (Sinclair, 2004). The findings of the studies support computers in mathematics teaching and learning. For example, Isikal and Askar (2005) investigated the effect of spreadsheet and dynamic geometry software on mathematics achievement and mathematics self-efficacy. The results indicate that using technology effectively as a learning tool improves students' mathematics achievement. Olkun et al. (2005) found that students who did not have computers at home initially had lower geometry scores. Therefore, Olkun (2005) suggests that in schools, it seems more effective to integrate mathematical content and technology in a manner that enables students to do playful mathematical discoveries. 
Sinclair (2004) found that using the Geometer's Sketchpad activities helps students notice geometric details, explore relationships and develop reasoning skills related to geometric proof.

On the other hand, research has examined preservice teachers views on instructional technology in teaching (Di, 1999;Wang, 2001; Beyerbach, 2001; Goos, 2005; Shamatha, 2004). Di (1999) examined the impact of instructional technology in an educational foundation course on student's perceptions of instructional technology. The results indicated that while utilizing the Internet for research, students improved their perception of instructional technology related to confidence and comfort level, frequency of computer use, and views on instructional technology in teaching. Wang (2001) investigated student teachers' perception and practice of the teacher's role when teaching with computers. The teacher's role was measured as teachercenteredness and student-centeredness, and results showed a significant difference in computer use although no difference in perception of use.

This paper examines the interview of ten pre-service teachers. These pre-service teachers were asked various questions about technology and the quality of training they received to prepare the pre-service teachers for teaching. Nine themes of the pre-service teachers responses were chosen and discussed.

\section{Purpose of the Study}

The purpose of the study was to design workshops with primary purpose of fostering teachers' confidence and their competent and fostering more positive attitudes toward using computers and Internet resources in the mathematics classroom. In addition, the purpose of the study was to examine whether these workshops achieved their aim and how.

\section{Research Questions}

Question 1: Do pre-service teachers perceive the importance of technology in enhancing mathematics learning and supporting effective mathematics teaching?

Question 2: How do pre-service teachers feel about using computers or Internet resources in teaching mathematics?

Question 3: Do pre-service teachers increase confidence and lessen anxiety toward using computers or Internet resources in teaching math attending webbased workshops on mathematics education?

\section{METHOD}

\section{Subjects}

The subjects of this study were undergraduate students from the preservice elementary education program. They were enrolled in the course, Mathematics
Content and Methods for the Elementary School course. The course offers students experience in developing mathematics lessons appropriate for elementary instruction based on an investigative approach to elementary mathematics instruction, which is purposeful, inquiry-based, and meaningful. In addition, students explore appropriate technologies that enhance mathematics instruction. Ten students were interviewed.

\section{Treatment}

In this study, students received six weeks instruction $(18 \mathrm{~h})$ in this study. Topics related to geometry, data analysis and probability were covered as part of the regular classroom curriculum in Mathematics Content and Methods for the Elementary School course. Students were trained about web-based instruction (Lin, in press) before treatment. The instructor introduced several interactive web sites which are appropriate for elementary students such as National Library of Virtual Manipulative (National Library of Virtual Manipulative, 2007) and Illuminations (National Council of Teachers Mathematics, 2007). Students explored the interactive web sites to get closer look of geometry. Next, students were asked to come up several different ways of solution and discuss in the classroom (Becker and Shimada, 1997; Hashimoto and Becker, 1999). For example, how many proofs of Pythagorean Theorem you can find on the internet? Students were not only asked how to find the answer but also were asked to discuss the reason why.

\section{Interviews}

\section{Purpose of the Interviews}

The purpose of the interviews was to confirm the students' level of computer competency and their understanding of the role of computers in promoting effective teaching and learning mathematics. In addition, the interviews investigated pre-service teachers' attitudes toward using computers and web-resources in teaching mathematics in elementary school. The interviews provide the opportunity for the interviewer to observe the subject and the whole situation in which he or she is responding. Questions can be repeated or their meanings explained in case they are not understood by the respondents. The interviews provided insight for the interpretation of the study.

\section{Procedure of the Interviews}

Interviews were conducted with 10 students. They were asked to participate in one 40-minute interview after the workshops. The interviews, were audio-taped 
with students' permission. The questions of the interviews were prepared but the interviews were conducted in a conversational method. The interviewer made sure that all questions were asked and a clear answer was given to each question. The following is a sample of the interview questions:

First Part: To what extent do you think about teaching mathematics with computers and web-based resources? Is it important? Why?

Second Part: How comfortable do you feel in using web-based resource in teaching mathematics?

Third Part: What aspects of the workshop in geometry were beneficial to you? What aspects of the workshop in data analysis were beneficial to you?

\section{Data Analysis}

For the qualitative research questions, to answer question one: "Do pre-service teachers perceive the importance of technology enhancing mathematics learning and supporting effective mathematics teaching? ", and question two: "How do pre-service teachers feel about using computers or Internet resources in teaching mathematics?", and question three: "Do pre-service teachers' attitudes toward using computers or Internet resources in teaching mathematics change after attending web-based workshops on mathematics education?". Interviews were employed.

\section{RESULTS}

The students' interviews consisted of three different sections of questions. Five themes were extracted from the interview data. Those themes include: prior experience with computers and web-based resources, using web-based resources in the mathematics classroom, importance of technology in the mathematics classroom, geometry workshop, and data analysis workshop

\section{Theme 1: Prior Experience with Computers and Web-based Resources}

The first theme is covered with pre-service teachers' prior experience with computers and using web-based resources. When asked how long they had been using computers, eight of the pre-service teachers responded that they had been using computers since kindergarten. However, seven of the pre-service teachers noted that their use of computers at a young age occurred primarily in their home. For example, Kim stated, "I've been using computers since I was about seven years old, and my dad has always had computers in the house... we've always had at least two". Lauren said, "My family got an Apple for me when I was three, my mom taught Apple workshops at a gifted school".
Three pre-service teachers reported using computers at school when in the elementary grades. For example, Lauren stated, "It started in 4th grade; my elementary school required that once a week we had computer time. We'd go for an hour, and learn how to type properly". Bridget said, "When I was in grade school, we had computers once a week, but there was no Internet connection with that. We would just play games". In addition, she indicated that some of the games that she played were Mathematics games where the player was given many problems in an attempt to get as many right as possible. Kristin said that in elementary school they only used the computers to play games related to Social Studies. Christine said that she was only taught how to type in elementary school, and in high school she used the computer primarily to type papers.

Three of the pre-service teachers started using computers at school in middle/junior high school. For example, Jennifer said that she used the computer for word processing as well as playing the game entitled "Oregon Trail". Kim said, "In eighth grade, we had to put together something about social studies...we just had to find things using the Internet... and put it all together in PowerPoint presentations". Molly stated "I would do mostly games, adventure and mathematics games".

Six pre-service teachers reported that while in high school they never used computers in their mathematics classes. For example, Kim said, "In mathematics, we just used calculators...we used a lot with graphical calculators". When asked about the use of computers in mathematics class, Molly responded, "Well not in high school. I went all the way up to AP-calc and we never used computers. Never had any supplement to the classroom instruction". In response to whether or not computers were in mathematics classes in school, Tara responded, "In mathematics, not really. Probably this year was the first year that I started using any kind of technology with mathematics".

In summary, it appears that very few of the preservice teachers had extensive exposure to using the Internet and web-based resources. Most pre-service teachers reported that they used it mainly for research for papers, to chat, or to check email accounts, and most of these activities were done from their home computer. The pre-service teachers' responses to the first question clearly indicate a lack of experience in using computers to a great extent prior to entering college. Several pre-service teachers did indicate that they had a computer in their home while growing up. However, many reported computer use in school at the elementary, middle/junior high, and high school level only for playing games or using word processing. 


\section{Theme 2: Using Web-based Resources in the Mathematics Classroom}

The second theme focused on pre-service teachers' beliefs about using web-based resources in the mathematics classroom. Pre-service teachers were asked whether they think web-based resources are enjoyable and stimulating, whether they like using webbased resources when teaching, as well as how comfortable and confident they feel about using webbased resources in the classroom.

When pre-service teachers were asked whether they like using web-based resources to teach mathematics, seven out of ten of the pre-service teachers stated that although they have not had the opportunity to do so, they do believe that they would like using web-based resources to teach mathematics. When asked whether they think web-based resources are enjoyable and stimulating several pre-service teachers respond positive. For example, Shea, said, "Definitely. In terms of teaching, definitely, because you get to see all the positive reactions from the kids. And in terms of students...you're getting hands-on computer work...they would actually be able to see the visuals on the computer...watching the students who normally don't succeed, to succeed, and in a different way". Kim stated, "I think its definitely enjoying for the kids, because a lot of them get discouraged with mathematics, it's just a bunch of numbers sometimes...kids don't visualize it, they don't really understand what's going on, and the computer can really help, just give them a visual picture of what's happening, so they can see it, and they can have fun, because they can play games and things too".

When asked how comfortable and confident they felt about using web-based resources in teaching mathematics. The majority of the ten pre-service teachers responded that they felt fairly comfortable with using web-based resources in the classroom. Kim said, "I feel that I'm comfortable in finding them. Once I find them, I think that I need to go through and play with that for a while by myself so I can find all the things you can do with each program or game...get questions more quickly, and save time in the classroom". Another pre-service teacher Molly said, "I feel sort of comfortable. I have a good start in thinking about what I'd like to do, and ideas about how to integrate it into the mathematics curriculum, but I don't feel totally confident yet, because I haven't used it yet'.

When asked how confident they feel about using web-based resources in the classroom,

six pre-service teachers felt that they were confident about using web-based resources in the classroom. For example, Shea explained, "Pretty confident...I have a good basis for it, and I know the resources to go to if I don't know the answers to my questions, and I think I have a good start to get my students involved in web- based resources for various subject matters". Two preservice teachers responded that they felt fairly confident in using web-based resources to teach. Christine expressed that she felt fairly confident saying, "I'm fairly confident that I will be able to grow professionally using technology in the next year, and be able to implement in my classroom, in mathematics, so I'm fairly confident, I think". Jennifer said, "I just feel that I haven't been introduced to many resources that are out there. I haven't really had the opportunity to try them in the classroom setting yet".

In summary, ten pre-service teachers indicated that using web-based resources in the classroom would be very enjoyable for them as well as for the students. All of the pre-service teachers stated in some way that they would easily be able to find the resources they needed, but would have to take time on their own to practice using them before implementing usage in the classroom. Overall, the majority seemed to be comfortable and confident with the idea of using web-based resources to teach mathematics.

\section{Theme 3: Importance of Technology in a Mathematics Classroom}

The third theme focused on the pre-service teachers' beliefs about the importance of technology in a mathematics classroom. Out of the ten pre-service teachers, nine reported technology and computers as an important part of teaching mathematics. Only one participant stated that using technology in the mathematics classroom was not important.

When asked why they felt that computers and technology is an important part of a mathematics curriculum, six of the pre-service teachers stated that computers are an important visualization tool. Further, they indicated that computers are an excellent tool for visual learners. For example, Tara said "Well, I think a lot of times, with students who are more visual, the websites that you can actually see, like the shapes, and the 3D sets, where you can actually play around with the different shapes, or something like that, its easier for them to understand the concepts, if they are more visual". Six pre-service teachers indicated that computers allow students visual representations that are often impossible to show with pen and paper or by simply using a chalkboard. In addition, computers' visual representations help students better understand different concepts.

Five pre-service teachers stated that computers and technology can help enhance Geometry, and four of the ten pre-service teachers indicated that computers allow for manipulation. For example, Christine said, "I think with Geometry you can do different angle construction, you can do many different things on there". Another pre-service teachers, Kim stated, "computers can show the visual aspect of it, a lot of kids can't visualize, say, 
shapes, they don't know what it looks like, and the computer is a really great way, especially like the Geometry website, the 3D shapes, to manipulate it, and have the kids look at it, and they wouldn't be able to do that as easily, you know just using paper".

Nine of the pre-service teachers stated that computers were an important part of mathematics because computers are a motivator for students, making mathematics more interesting. Six of the ten pre-service teachers stated that using computers as part of a mathematics curriculum motivates students. Kristin stated, "I think computers makes them more interested in mathematics, because, its very colorful and exciting for them, and I think it might make them more excited about Mathematics". Kristin continues, "Kids love getting on the computer, and a lot of these, games...so they're learning, but they're also having fun with the game-type atmosphere". Rahwa said, " computers are a motivator for students due to the fact that kids love getting on the computer". When she was asked why, she stated, "I think they see it as being fun and something exciting and new. And if they get to do their Math problems on the computer, I think that would motivate them to actually do their work".

Three of the ten pre-service teachers mentioned that with computers being such an important part of society and many jobs demanding computer skills, it is necessary for students to be exposed to computers and computer programs and software. Molly said, "so much of our society depends on technology....There's endless applications, so they need to know it". Jennifer said, "it will help them become familiar with computers... and activities they can do using computers on the internet...if the resources are available".

In summary, a majority of pre-service teachers view computers as important in a mathematics classroom. They indicated computers provide a visual representation of a certain concept that is difficult to understand by using paper and pencil only. They can help enhance Geometry concepts because they allow for manipulation. In addition, computers also provide motivation for students in making mathematics more interesting.

\section{Theme 4: Geometry Workshop}

The fourth theme focused on the workshop in Geometry. When asked pre-service teachers about what aspect of the workshop in Geometry was beneficial to them. All of the ten pre-service teachers' responses were positive. Three pre-service teachers mentioned the Tangram program to get ideas across to kids as the biggest benefit from the workshop on Geometry. For example, Molly said" I thought the one the Tan-gram one was really neat, because you really needed some logic to figure out how am I going to put these shapes together, to form the shape that they're showing me..it's challenging." Kristin stated," Well what I remember doing was the Tangram sheets, where you had to put them in there, and just the different patterns, and I enjoyed the site that incorporated music into the different patterns."

Three pre-service teachers reported that the Geoboards program was their biggest benefit from the workshop on Geometry. For example, Tara said," Students are able to manipulate like in the GeoBoard website, they're able to play around with it, with colors."

Three pre-service teachers reported that the 3-D program was their biggest benefit from the workshop on Geometry. Lauren said," My favorite website that we were introduced to was the one with the geometric solids and their properties. We got to look at these 3D shapes, as they rotated, and change the color ot the faces, change the volumes, the measurements, and explore the shapes from various angles." Christine said," I think the 3D website...I think that the kids, if they were using that, you can't really bring that to life the way it could happen on the computer, in the classroom. The kids can zoom in and see different things that they wouldn't be able to normally see without that tool. I could definitely integrate that in a unit on Geometry."

When asked whether the workshop helped them to feel less anxious about using computers when teaching Geometry, nine of the ten students felt that their confidence was greater and anxiety was less from taking the workshop on Geometry. For example, Christine stated" Yeah. I feel like I have more tools to rely on, when using technology." Shea said," Yeah. Because they gave me specific places to go, when I have...for example if I'm going to do Shapes today, as an activity to that I would do Tan-grams, and have them explain the shapes." Kristin said," Yes. Because it gave me these websites that I didn't realize were out there to use. And I think that being shown that in class gave me more confidence that there's these great resources out there that I can pull from and use in my classroom."

\section{Theme 5: Data Analysis Workshop}

The fifth theme focused on the workshop on Data Analysis. When pre-service teachers were asked about what aspect of the workshop in Data Analysis was beneficial to them. All of ten pre-service teachers responded positively. Five out of ten pre-service teachers mentioned the Create-a-graph program was the biggest benefit from the workshop on Data Analysis. For example, Molly said "I liked the Create-a-graph, where they give you different options of the graph, it wasn't just a line graph or a bar graph, it gave you a lot of different options to explore this." Kristin replied," I think that the graph simulators were good...the different kinds of graph that they had...you could show the kids, you know you have this data, and a bar graph, or a line 
graph, just all the different things, I think that those were good examples."

Three pre-service teachers mentioned the probability coin-tossing program to get ideas across to kids as the biggest benefit from the workshop on Data Analysis. Kim said, "like the coin-flipping with probability, its just something, if the kids were flipping coins, it would take them a really long time, and it might be good to have them do that for 10, 20 trails, but they can't do 10,000 flips and the computer can do that in just seconds". Tara said, "I think with the websites that we looked at, like the coin toss websites, it was good because it was one of those things that I could see kids wanting to plug in a number, and see, will it still be half and half, or if I flip it this many, 10000 times."

When asked whether the workshop helped them to feel less anxious about using computers when teaching Data Analysis, nine of the ten students felt that their confidence was greater and anxiety was less from taking the workshop on Data Analysis. Christine when asked about the workshop increasing confidence and reducing anxiety responded, "Oh definitely. Because I know that I just go there and search for it and understand how it works, and yeah, definitely". Christine said," Oh, definitely. Definitely.....Well I mean, when you just think of approaching a topic using technology, you don't even know where to start. I mean, there could be a lot of programs out there that you could use, you could search the internet for different things, but now I have something, you know." The only one to show any doubt was Jennifer, who said, "I've been introduced to it, and I've seen how it could work in a classroom, so I feel like I could bring this into my classroom, but I'm not completely confident about that". She sees how it works and understands what it can be used for, but lacks the confidence in her abilities.

In summary, the pre-service teachers expressed the desire to integrate the use of technology in their classroom instruction. They felt that using the mathematics textbook often creates a dull classroom. It appears that the participants believe that integrating hands-on activities with physical manipulatives as well as computer resources will engage the students in their learning and lead to a better understanding of the content.

\section{CONCLUSION}

The interviews results showed that all of the interviewees agreed that computers and web-based resources are very important and they helped their students to learn mathematics. Generally, most of them agreed that computers provide a visual representation, the $3 \mathrm{D}$ shapes, which helped them to understand more of what was going on. In addition, they thought it was very colorful and exciting for younger children, and they thought it might make them more excited about mathematics. One student said, "I think mainly because they can show the visual aspect of it, a lot of kids can't visualize, say, shapes, they don't know what it looks like, and the computer is a really great way, especially like the Geometry website, the 3D shapes, to manipulate it, and have the kids look at it, and they wouldn't be able to do that as easily, you know just using paper." Another student said, "it gives that visual representation, and it kind of gives them more hands on things ....I think it makes them more interested in it, because, it's very colorful and exciting for them, and I think it might make them more excited about mathematics."

In addition, some students agreed that integrating computers or Internet resources into teaching mathematics are important because we are moving into a technological age and computers provide an efficient way and variety of learning. One student said, "I do think it's important for them to become computersavvy, because we're moving into a technological age. And I think it's also important because the web provides a lot of resources for free...it's important also because you can provide your students with a wide variety of learning." Another student said, "I think it's a more efficient way of doing things, if you're going to look at, like the probability things, you can do spreadsheets and things like that that are going to be more efficient ways of doing that, and that will be more important for students to know. Both for teachers to keep track of data, and for students to learn, later in life, to keep track of those kinds of things."

The results of this study are in agreement with Alghazo (1999). They found that preservice teachers appreciated the importance of integrating technology into teaching. When asked about whether they plan to integrate computers and Internet resources into their mathematics teaching, all of the students answered that they plan to use computers and Internet resources in teaching mathematics. Moreover, some students said that they would consider computers as a supplement to be used after lecturing to students. Other students said that they would use both computers and manipulatives to teach mathematics in the future. The findings of this research are also in agreement with NCTM Technology Principle (2000) "Technology enhances mathematics learning" and "Technology supports effective mathematics teaching."

The results of the interviews indicated that most of the students felt confident and comfortable using webbased resources in teaching mathematics. In addition, most of the students felt that they were prepared to teach mathematics with technology. Two of the students said that they felt a little uneasy if they used computers in teaching mathematics. Most of the students said that using web-based resources in teaching mathematics would be enjoyable and stimulating 
because it was very "visual" and "interactive". One student answered, "I think I would be very comfortable. It's fun for me. It's fun for the kids, and one great thing is that a lot of kids out there do know how to use computers, so they're willing to help or share their knowledge. It's a great way to get the kids to help me teach." Another said, "I think that they would be very stimulated, because of the way it's set up, you know those sites that you gave us, as I said before are very colorful and fun. And its not the kids at the desks with pencil and paper and filling out facts .. even though they might still be getting those facts through the computer program, it's a lot more interesting and exciting for them, and I think that the kids would always want to play on the computer and do things, and I think that this would be a great thing for them to do."

The results of this study are in agreement with NCTM (2000) "Technology can help students learn mathematics... The graphic power of technological tools affords access to visual models that are powerful but that many students are unable or unwilling to generate independently. The computational capacity of technological tools extends the range of problems accessible to students and also enables them to execute routine procedures quickly and accurately, thus allowing more time for conceptualizing and modeling."

The results show that all students agreed that the workshops were helping them increase their confidence and they felt less anxious in using computers to teach mathematics. They all agreed that they learned a lot since they got to the workshops. Most of them said that the most beneficial thing that they have leaned from the workshops is how to find a good resource in mathematics for elementary students. One student said, "Definitely, to teach Geometry, because I was shown different options to teach Geometry using computers to teach it. I wouldn't have thought of it before, because I hadn't seen it. I didn't realize the resources were out there." Another student said, "It showed me a lot of the resources that I could go to, to find activities for the kids to do on computers, that I didn't know existed. I mean I knew you could find mathematics lesson plans, but I'd never seen these fun games, like the Tan-grams, never seen those before."

In terms of geometry in the workshops, many students said they liked the Tan-gram activity. One student said, "I thought the one the Tan-gram one was really neat, because you really needed some logic to figure out how am I going to put these shapes together, to form the shape that they're showing me .. It's challenging .. I find myself being challenged by it, and you really have to use your logic and your spatial skills to figure it out. I think that kids benefit from that, because it's interactive. They're trying to figure out a problem, its really enhancing their problem solving. I think that you could do Tan-grams with paper and other materials, but the difference is the exposure to technology. That's good for them. And of course it will generate the different shapes for them, instead of handing them a different sheet of paper that has that shape, too. I think that would be beneficial, but I think technology has more benefits with that. I really liked the Create-a-graph, where they give you different options of the graph; it wasn't just a line graph or a bar graph. It gave you a lot of different options. To explore this." Other said, "The websites, the specific websites. I remember the Tan-grams one. Yeah and I really liked that..., because I would also use the manipulative Tangrams, so they could see those and feel those, and move them around physically, and then they could go the computer and move the pieces around on the computer screen, and that would be a different method of learning that maybe some kids would be able to pick up otherwise. So I think incorporating ... different ways of conveying the information to the students."

Based on the results, we found that the workshops were successful in changing students' attitudes toward using computers or Internet resources in teaching mathematics. The results of this study are in agreement with those of Alghazo (1999) and Yildirim (2000) who found that pre-service teacher computer training course would help them to improve attitudes toward using technology in the classroom.

\section{ACKNOWLEDGEMENTS}

The author wishes to thank Kenneth J. Travers, Jerry P. Becker, Katherine E. Ryan, Klaus G. Witz, Ian D. Westbury, and three anonymous reviewers for their helpful comments on an earlier draft of this article.

\section{REFERENCES}

Alghazo, I. M. (1999) A study of the technology competencies of preservice secondary mathematics teachers. Unpublished doctoral dissertation, University of Illinois, UrbanaChampaign.

Becker, J.P. and Lin, C.Y. (2005). Effects of a computational skills workshop on preservice elementary teachers. Preliminary report. Paper presented at the Annual Meeting of the Mathematical Association of American and the American Mathematical Society, Atlanta, GA.

Becker, J. P. and Shimada, S. (Eds.) (1997). The Open-Ended Approach-A New Proposal for Teaching Mathematics. Reston, VA: National Council of Teachers of Mathematics.

Beyerbach, B., Walsh, C., Vannatta, R. (2001) From teaching technology to using technology to enhance student learning: Preservice teachers' changing perceptions of technology infusion. Journal of Technology and Teacher Education $_{2}$ 9(1), 105-27.

Di, X., et al (2000). An integrated approach to instructional technology. Action in Teacher Education, 22(2), 1-13. 
Doering, A.,Huffman D., Hughes, J., Preservice Teachers (2003) Are We Thinking with Technology? Journal of Research on Technology in Education, 35.

Goos, M. (2005). A sociocultural analysis of the development of pre-service and beginning teachers' pedagogical identities as users of technology, Journal of Mathematics Teacher Education, 8(1), 35-59.

Isiksal, M.; Askar, P. (2005) The effect of spreadsheet and dynamic geometry software on the achievement and self-efficacy of 7 th-grade students. Educational Research, 47 (3), 333-350.

Lin, C. Y. (in press). Preservice teachers' beliefs about using technology in the mathematics classroom. Journal of Computers in Mathematics and Science Teaching.

National Council of Teachers of Mathematics (2000). Principles and standards for school mathematics, Reston, VA: Author.

Olkun, S., Altun, A., Smith, G. (2005). Computers and 2D geometric learning of Turkish fourth and fifth graders. British Journal of Educational Technology, 36(2), 317-326.

Sinclair M. (2004). Working with accurate representations: the case of preconstructed dynamic geometry sketches. Journal of Computers in Mathematics and Science Teaching, 23(2), 191-208.

Shamatha, J. H. Peressini, D., Meymaris, K. (2004). Technology-supported mathematics activities situated within an effective learning environment theoretical framework._Contemporary Issues in Teacher Education, 3(4), 362-381.

Wang, Y. (2001).Student teachers' perception and practice of the teachers' role when teaching with computers. Journal of Educational Computing Research, 24(4), 419-434.

Yildirim, S. (2000). Effects of an educational computing course on preservice and inservice teachers: A discussion and analysis of attitudes and use. Journal of Research on Computing in Education, 32(4), 479-495. 